\title{
PERANCANGAN SISTEM MANAJEMEN GUDANG MATERIAL RESIN DI PT. II
}

\author{
${ }^{1}$ Ossa Sutaarga, ${ }^{2} \cdot$ Dian Friana Hidayat \\ 1,2. Staff Pengajar Program Studi Teknik Industri, Fakultas Teknik \\ Universitas Muhammadiyah Tangerang \\ Jl. Perintis Kemerdekaan I/33, Cikokol, Kota Tangerang \\ Email : ossa.sutaarga@gmail.com, dianfriana@gmail.com
}

\begin{abstract}
A b strak
Management system at Resin warehouse in PT II still has many problems within. Improvement in management system needs to be done to overcome that problem. The difference between actual product's amounts and the record, unscheduled planning production, and unorganized warehouse layout are the problem of this company. Improvement for the record of actual product inside warehouse isn't to match the record of administration record. This process would be necessary to reduce the gap in stock opname process. MPS can be use to determine the ideal time and the ideal amount of total production for company, so that the inventory cost could be reduced. And then maximal capacity at Resin warehouse increase to $270 \%$ and increase the area until $26 \%$ squaremeter. Inventory turn over in the warehouse became better. The day sale in inventory was reduced from 17 days to 16 days.
\end{abstract}

Kata Kunci : warehouse management system, FIFO, ERP, KANBAN, Layout

\section{PENDAHULUAN}

PT. II adalah salah satu perusahaan industri bergerak dibidang Fibreglass Reinforce Plastic terbesar di Indonesia. Output yang dikeluarkan oleh PT tersebut adalah Fibreglass yang diolah sebelumnya dengan campuran bahan-bahan kimia seperti Resin, Mat, dan Katalis. PT. II ini memiliki beberapa gudang material, salah satu gudang tersebut adalah Gudang Material Resin. Lalu PT. II ini memiliki permasalahan utama yang ada pada gudang Resin tersebut yaitu sering terjadi kesalahan perhitungan material di dalam gudang. Kesalahan dalam perhitungan material tersebut terjadi karena perhitungan yang masih dilakukan secara manual dan kurangnya form-form pencatatan di dalam proses keluar masuk gudang.

Pengambilan produk yang tidak FIFO. Sistem penataan barang-barang yang ada di gudang tepung juga masih tidak beraturan. Hasil produksi langsung diletakkan dan disusun sesuai keinginan pekerja tanpa ada aturan penataan yang jelas. Tujuan dari penelitian ini terdiri dari 3 macam. Tujuan pertama adalah menentukan dan merancang perbaikan pencatatan saat proses keluar masuk produk di gudang untuk mengurangi perbedaan saat stock opname. Tujuan kedua adalah menentukan perencanaan produksi yang baik dan ideal bagi perusahaan. Tujuan Ketiga adalah Merancang aturan penataan, layout gudang dan flow keluar masuknya produk di dalam gudang agar sesuai dengan prinsip FIFO.

\section{METODE PENELITIAN}

Metode yang digunakan dalam penelitian ini digunakan untuk perbaikan pencatatan keluar masuk produk, perbaikan perencanaan produksi, perbaikan layout, flow keluar masuk produk dan aturan penataan produk di gudang.

\section{a. Perbaikan Pencatatan Keluar Masuk Produk}

Perbaikan pencatatan menggunakan Software ERP agar saat keluar masuk produk yang baru ini bertujuan untuk dapat mengurangi jumlah perbedaan produk antara kondisi fisik dengan Software ERP yang ada pada saat stock opname. Perancangan yang dilakukan ada dengan memperbaiki proses pencatatan barang keluar masuk dan meng-update kedalam software ERP tersebut. 


\section{b. Perbaikan Perencanaan Produksi}

Menentukan kapan dan berapa jumlah produk ideal untuk dipesan atau diproduksi oleh perusahaan. Hasil perencanaan produksi yang didapatkan ini akan dibandingkan dengan keadaan perusahaan sekarang dengan menggunakan data masa lalu perusahaan. Parameter yang digunakan adalah biaya simpan dan nilai inventory turnover. Hasil yang memberikan biaya simpan lebih rendah dan nilai inventory turnover yang lebih baik bagi perusahaan itulah yang merupakan metode yang lebih ideal untuk perusahaan.

\section{c. Perbaikan Layout, Flow Keluar Masuk Produk dan Aturan Penataan di Gudang}

Perancangan layout, flow keluar masuk produk dan aturan penataan yang ada di gudang ini bertujuan untuk memperbaiki keadaan layout gudang sehingga prinsip FIFO yang masih belum bisa diterapkan dapat berjalan dengan baik.

\section{HASIL DAN PEMBAHASAN}

Hal yang akan dibahas antara lain penyelesaian masalah ketidaksesuaian jumlah fisik produk yang ada di gudang dengan catatan yang ada, perencanaan produksi, penyelesaian masalah Kesalahan dalam pengambilan produk yang tidak sesuai dengan prinsip FIFO.

\section{a. Penyelesaian Masalah Ketidaksesuaian Jumlah Fisik Produk yang Ada di Gudang dengan Catatan}

Ketidaksesuaian antara jumlah barang aktual dengan catatan/data yang ada dapat terjadi oleh beberapa macam faktor yang mempengaruhi. Berikut adalah beberapa macam faktor yang dapat mempengaruhi ketidaksesuaian tersebut beserta rancangan perbaikannya.

\section{Perhitungan yang Masih Menggunakan Metode perhitungan Manual}

Rancangan perbaikan yang dapat dilakukan untuk dapat mengurangi kesalahan di dalam proses pencatatan saat terjadi kelebihan atau kekurangan muatan adalah dengan memodifikasi surat muat. Modifikasi surat muat menjadi Kanban.

Kanban tersebut bertujuan mengurangi kesalahan yang akan terjadi diakibatkan kelalaian Kepala Bagian Gudang untuk menuliskan berapa jumlah muatan yang telah dikurangi atau ditambahkan. Rancangan surat muat yang baru ini dibuat agar secara tidak langsung Kepala Bagian Gudang harus melakukan pencatatan berapa jumlah material Resin yang disiapkan untuk proses produksi.

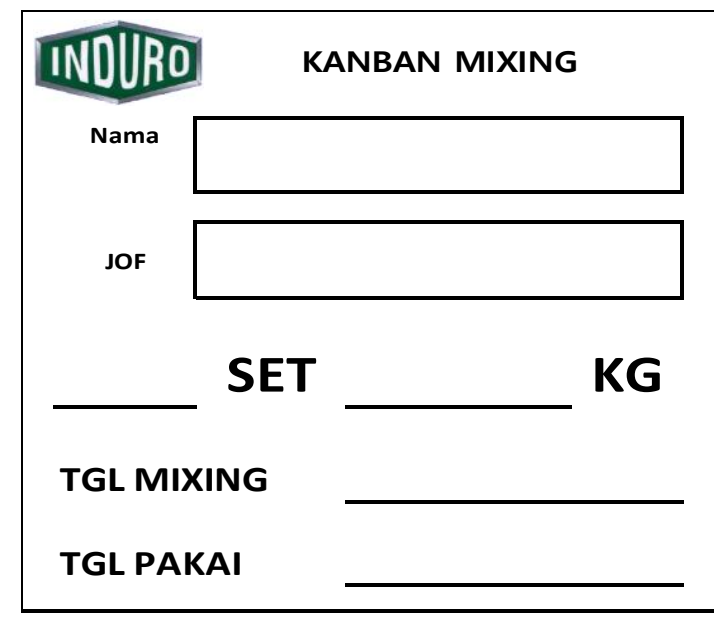

Gambar 1 Kanban Mixing 


\begin{tabular}{|c|c|c|c|c|}
\hline \multicolumn{2}{|c|}{ SUPPLIER } & \multicolumn{2}{|c|}{ KANBANTAG } & PLANTCODE \\
\hline \multicolumn{2}{|c|}{ MIXING WAREHOLSE } & \multirow{2}{*}{\multicolumn{2}{|c|}{$\begin{array}{l}\text { PT. II } \\
\text { INDONESIA }\end{array}$}} & PLANT EXT \\
\hline $\begin{array}{c}\text { DELIVERY } \\
\text { TO }\end{array}$ & PRO-GEN & & & \\
\hline DATE & $\begin{array}{l}\text { 22-DEC- } \\
2016\end{array}$ & \multirow{3}{*}{\multicolumn{2}{|c|}{$\begin{array}{c}\text { RESIN TYPE } \\
\text { RS570 }\end{array}$}} & \\
\hline 08:00 & $08: 20$ & & & \\
\hline CYCLE & \multirow{3}{*}{ 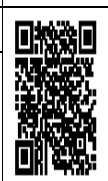 } & & & \\
\hline & & PACKING & DRUM & \\
\hline & & & $410 \mathrm{Kg}$ & \\
\hline
\end{tabular}

Gambar 2 Kanban Tag ERP

Rancangan perbaikan yang dapat dilakukan untuk menyelesaikan masalah perhitungan ini adalah dengan melakukan improvement pada proses Mixing Material, dimana proses tersebut melakukan aktivitas pencampuran material Resin dengan material kimia lainnya. Dengan menggunakan Kanban Mixing maka proses tersebut sudah ditentukan Jumlah Resin yang digunakan, Kapan Resin akan dimixing, dan penggunaan Resin untuk proses produksi apa. Perbaikan yang dilakukan adalah Operator membaca perintah dari Kanban tersebut lalu mengaplikasikan untuk aktivitas mixing. Setelah aktivitas mixing selesai maka Kanban mixing tersebut akan di catat oleh admin gudang dan di Input ke dalam Software ERP.

Dengan adanya Kanban tag maka keakuratan stock penggunaan Resin di software ERP dengan actual diharapkan mencapai $100 \%$. Karena sifat dari kanban tag ini adalah total yang dibutuhkan, resin apa yang dibutuhkan, dan kapan dibutuhkan. Jadi kondisi yang didapat di software ERP pabrik adalah kondisi actual lapangan pada saat itu juga.

\section{Perenacanaan Produksi}

Perencanaan produksi dapat membantu menentukan berapa jumlah produk yang harus diproduksi untuk dapat memenuhi semua permintaan. Perencanaan produksi yang ideal dapat mencegah terjadinya kelebihan stok pada gudang. Hal ini dapat membuat proses FIFO dapat berjalan dengan baik karena produk jadi yang menumpuk di dalam gudang Resin berkurang, sehingga aliran proses keluar masuk Material Resin dapat berjalan lancar. pembuatan MPS (Master Production Schedule) penguunaan material Resin. Jumlah kebutuhan material resin periode November 2017 akan digunakan sebagai acuan di dalam pembuatan peramalan kebutuhan material Resin ke depannya. Peramalan kebutuhan material Resin.

\begin{tabular}{|c|c|c|c|c|c|c|c|c|c|c|c|c|c|c|c|c|c|c|c|c|c|c|}
\hline $\begin{array}{c}01 / 11 / \\
16 \\
\end{array}$ & $\begin{array}{c}02 / 11 / 1 \\
6\end{array}$ & $03 / 11 / 16$ & $\begin{array}{c}04 / 11 / 1 \\
6\end{array}$ & \begin{tabular}{|c}
$05 / 11 /$ \\
16
\end{tabular} & \begin{tabular}{|c}
$07 / 11 /$ \\
16
\end{tabular} & \begin{tabular}{|c}
$08 / 11 /$ \\
16
\end{tabular} & \begin{tabular}{|c}
$09 / 11 /$ \\
16
\end{tabular} & \begin{tabular}{|c}
$10 / 11 /$ \\
16
\end{tabular} & $\begin{array}{c}11 / 11 / \\
16\end{array}$ & $\begin{array}{c}14 / 11 / \\
16\end{array}$ & \begin{tabular}{|c|}
$15 / 111$ \\
16 \\
\end{tabular} & \begin{tabular}{|c|}
$16 / 111$ \\
16 \\
\end{tabular} & \begin{tabular}{|c|}
$17 / 111$ \\
16 \\
\end{tabular} & $\begin{array}{c}18 / 111 \\
16 \\
\end{array}$ & $\begin{array}{c}21 / 11 \\
16\end{array}$ & $\begin{array}{c}22 / 111 \\
16 \\
\end{array}$ & \begin{tabular}{|c|}
$23 / 111$ \\
16 \\
\end{tabular} & \begin{tabular}{|c|}
$24 / 111$ \\
16 \\
\end{tabular} & $\begin{array}{c}25 / 11 / 1 \\
6\end{array}$ & $\begin{array}{c}28 / 11 / \\
16\end{array}$ & \begin{tabular}{|c|}
$29 / 111$ \\
16
\end{tabular} & \begin{tabular}{|c|}
$30 / 111$ \\
16 \\
\end{tabular} \\
\hline & & & & & & & & & & & & & & & & & & & & & & \\
\hline & & 4 & 4 & & & & & & & 2 & 4 & & & & & & & & & 5 & 5 & 5 \\
\hline & & 4 & 4 & & & & & & & 2 & 4 & & & & & & & & & 4 & 5 & 4 \\
\hline & & 87.8 & 87.8 & & & & & & & \begin{tabular}{|l|l|}
43.9 \\
\end{tabular} & \begin{tabular}{|l|}
87.8 \\
\end{tabular} & & & & & & & & & \begin{tabular}{|l|}
110 \\
\end{tabular} & 110 & 110 \\
\hline & & 96.58 & 96.58 & & & & & & & \begin{tabular}{|l|l|}
43.9 \\
\end{tabular} & 87.8 & & & & & & & & & 87.9 & 110 & 87.8 \\
\hline & & & & & & & & & & \begin{tabular}{|l|}
2 \\
\end{tabular} & & & & & & & & & & & & \\
\hline & & & & & & & & & & 2 & & & & & & & & & & & & \\
\hline & & & & & & & & & & 43.9 & & & & & & & & & & & & \\
\hline & & & & & & & & & & 43.9 & & & & & & & & & & & & \\
\hline & & & & & & & & 4 & 4 & 4 & & & & & 4 & & & & & & & \\
\hline & & & & & & & & 4 & 4 & 4 & & & & & & & & & & & & \\
\hline & & & & & & & & 99 & 99 & 99 & & & & & & & & & & & & \\
\hline & & & & & & & & 99 & 99 & 99 & & & & & & & & & & & & \\
\hline
\end{tabular}

Gambar 3 Master Production Schedule 


\section{b. Pembuatan MPS (Master Production Schedule) Dalam Proses Mixing}

Pembuatan MPS (Master Production Schedule) diperlukan untuk membuat perencanaan mixing material resin yang ideal bagi perusahaan. Jumlah maksimum proses mixing dihasilkan rata-rata sebesar $410 \mathrm{Kg} / \mathrm{hari}$, maka Nilai MPS yang akan diproduksi dalam sekali proses mixing adalah sebesar $9020 \mathrm{Kg} /$ Bulan (1 bulan sama dengan 22 hari kerja. yang didapatkan dari nilai rata-rata dikali 22 hari kerja.

\section{c. Perhitungan Biaya Simpan Produk Jadi Kondisi Awal Perusahaan}

Perhitungan biaya simpan produk jadi awal perusahaan dapat dihitung dengan menggunakan data jumlah produk keluar, jumlah produk masuk, jumlah stok awal, harga jual produk perpemakaian Resin (asumsi @ 410 kg/hari) dan periode perhitungan. Biaya simpan produk diasumsikan sebesar $0.15 \%$ dari harga jual produk. Asumsi tersebut disesuaikan dengan suku bunga deposito bank BII pertahun yang telah dikonversikan menjadi perperiode. Periode perhitungan adalah satu minggu. Harga jual produk perkilo Resin adalah Rp 91.000,00. Stok awal produk di gudang $17.458 \mathrm{Kg}$. Biaya simpan setiap drum Resin $(220 \mathrm{~kg})=91000 \times 220 \times 0,15 \%=\mathrm{Rp} 30.030$.

\section{d. Perhitungan Inventory Turn Over pada Kondisi Awal Persediaan di Gudang}

Perhitungan Iventory Turn Over ini dilakukan untuk menghitung jumlah perputaran produk di gudang yang dialami oleh perusahaan setiap bulan.

- Inventory turnover $=$ cost of goods sold $\div$ average cost of goods stored

- Jumlah drum keluar bulan November $=88$ Drum

- $\quad$ Rata-rata jumlah stok bulan November $=70$ Drum

- Inventory turnover $=$ jumlah produk keluar $\div$ rata-rata jumlah stok di gudang $=1.25$ kali

Days Sales in Inventory $\quad=22 \div 1.25$

$$
=17.6 \text { hari }
$$

Nilai dari Days Sales in Inventory pada bulan November 17.6 Hari menunjukkan bahwa perputaran produk yang ada di gudang adalah setiap 17 hari. Maka setiap 17 hari Resin akan habis diproses mixing dan berganti dengan kedatangan resin yang baru dari supplier.

\section{e. Perhitungan Biaya Simpan Perusahaan dengan Metode Usulan}

Perhitungan dengan menggunakan rancangan MPS digunakan untuk menentukan berapa dan kapan resin harus diproses dengan menggunakan demand aktual. Tujuan dari penggunaan rancangan MPS ini adalah untuk dapat mengurangi biaya simpan yang dikeluarkan oleh perusahaan dan mengatur agar aliran produksi menjadi lebih lancar. Untuk menghitung Stok awal maka perhitungan dilakukan stok akhir periode 1 menjadi stok awal periode 2 . Jumlah proses mixing disesuaikan dengan nilai MPS sebesar $410 \mathrm{Kg} /$ Hari. Produksi sebesar MPS dilakukan tiap hari sesuai dengan permintaan dari Kanban Tag.

\section{f. Perhitungan Inventory Turnover Perusahaan dengan Metode Usulan}

Perhitungan iventory turnover pada kondisi persediaan yang menggunakan rancangan MPS ini dilakukan untuk menghitung jumlah perputaran produk di gudang yang dialami oleh perusahaan setiap bulannya. Perhitungan jumlah inventory turnover dengan menggunakan rancangan MPS dapat dihitung dengan menggunakan rumus

Inventory turnover $=$ cost of goods sold $\div$ average cost of goods stored

Jumlah Drum keluar bulan Desember $=93$ Drum

Rata-rata jumlah stok bulan Desember $=70$ Drum

Inventory turnover $\quad=1.32 \mathrm{kali}$

Days Sales in Inventor $\quad=22 \div 1.06$

$$
=16.6 \text { hari }
$$

Perputaran produk di gudang adalah setiap 16 hari. Setiap 16 hari produk akan habis terjual dan berganti dengan produk yang baru. 


\section{g. Penyelesaian Masalah Kesalahan dalam Pengambilan Produk yang Tidak Sesuai dengan Prinsip FIFO}

Faktor yang menyebabkan kesalahan di dalam pengambilan barang adalah kesalahan dalam layout, penataan dan aliran flow keluar masuk produk di gudang. Rancangan perbaikan layout gudang diperlukan untuk memperbaiki kesalahan dan kekurangan yang ada pada layout gudang yang lama. Perbaikan tersebut dilakukan dengan meperhatikan beberapa pertimbangan sehingga prinsip FIFO dapat berjalan dengan baik di gudang.

\section{h. Layout Awal Gudang Tepung}

Jumlah drum maksimum yang dapat disusun didalam gudang dapat dihitung sebagai berikut

$$
\begin{array}{ll}
1 \mathrm{~m}^{2} \text { luas lahan } & =1 \text { drum Resin } \\
\text { Luas lahan penataan } & =336 \mathrm{~m}^{2} \times 1 \text { drum } \\
& =336 \mathrm{drum}
\end{array}
$$

Jumlah maksimum drum yang dapat disusun di dalam gudang adalah sebanyak 336 Drum Resin. Luas area sudah dikurangi dengan luas area untuk pejalan untuk perpindahan barang, mengatur barang dsb. Selain itu luas area gudang tersebut dilakukan untuk penyimpanan material lain, maka dapat dihasilkan luas area sebesar $336 \mathrm{~m}^{2}$.

Proses mixing resin berjalan selama 8 jam kerja/hari, sedangkan proses penataannya hanya dilakukan ketika ada pengambilan dan kedatangan Drum Resin. Perbedaan jam kerja tersebut menyebabkan terjadinya banyak drumresin yang tidak sempat tertata dan diletakkan diluar gudang. Jajaran drum yang disimpan diarea depan gudang resin ini menyebabkan akses jalan pengambilan resin untuk di proses mixing maka produk tertutup. Hal tersebut menyebabkan seringnya terjadi kesalahan di dalam proses pengambilan produk yang tidak sesuai dengan urutan tanggal produksinya. Produk dengan tanggal produksi yang lebih awal dan seharusnya dimuat terlebih dahulu akan kesulitan untuk diangkut karena akses jalannya tertutup oleh drum yang belum tertata.

\section{i. Usulan Rancangan Layout Gudang Baru}

Sistem penataan, letak susunan dan alur keluar masuk untuk produk pada layout baru sedikit diubah dari sistem awal. Lokasi penataan drum akan dimaksimalkan diarea tersebut dengan cara menumpuk resin 1 tingkat diatasnya, mengelompokan dan memisahkan Drum resin dengan material lain yang ada di Gudang Resin tersebut. Hal ini berfungsi untuk memudahkan Kepala Bagian Gudang di dalam mengidentifikasi jumlah drum resin, mengelola drum resin dan penyesuaian transfer resin ke gudang mixing sesuai dengan tanggal proses mixing. Satu blok sama dengan $1 \mathrm{~m}^{2}$ saat ini bisa diisi dengan 2 drum resin, selain itu material selain resin tidak boleh ada di area gudang resin. Luas area sebelum perbaikan layout hanya $336 \mathrm{~m}^{2}$, setelah perbaikan luas area maksimal mencapai $457 \mathrm{~m}^{2}$. Maka jika dihitung untuk kapasitas maksimal resin digudang resin tersebut meningkat $26 \%$. Lalu total kapasitas drum muat menjadi $1 \mathrm{~m}^{2}$ x 2 x $457 \mathrm{~m}^{2}=914$ drum Resin. Kapasitas maksimal drum resin ini meningkat sekiranya $270 \%$ dari total kapasitas maksimal gudang resin.

Gudang Resin pada awalnya kesulitan dalam melakukan FIFO dikarenakan proses pengambilan dan kedatangan yang dibuat dari 1 arah. Setelah perbaikan maka gudang tersebut dibuatkan 2 pintu yaitu 1 pintu untuk kedatangan Drum Resin lalu 1 pintu lagi untuk pintu keluar menuju gudang mixing. Jadi untuk pengaturan kedatangan material yang datang lebih dulu bisa disimpan dekat dengan pint keluar, lalu jika ada kedatangan drum resin berikutnya bisa disimpan dibelakang batch pertama. Penyusanan drum resin ini sesuai dengan batch kedatangan drum tersebut. Lalu untuk flow pemindahan drum resin bersifat 1 arah. Jadi kepala gudang tidak akan kesulitan dalam mengalokasi drum tersebut ke gudang mixing.

\section{KESIMPULAN}

Rancangan perbaikan berupa perbaikan sistem perhitungan dan perbaikan nota-nota untuk proses di dalam gudang yang bertujuan mengurangi perbedaan jumlah fisik di gudang dengan menambahkan software ERP dan dikombinasikan dengan Kanban Tag. Diharapkan dengan adanya kanban tag tersebut maka keakuratan barang fisik dan program mencapai $100 \%$, dengan catatan operator yang diberi. 
Wewenang menjalankan kanban tag harus update sesuai dengan waktu aktual. Parameter keberhasilan perancangan produksi yang lain adalah melalui inventory turn over, yaitu yang awalnya berkisar 17 hari menurun menjadi hanya 16 hari secara rata-rata. Rancangan layout dan aturan penataan membuat prinsip FIFO perusahaan menjadi lebih baik dengan kapasitas maksimal mencapai 2.7 kali lipat dari sebelumnya. Luas area pun meningkat setelah perbaikan mencapai $26 \%$.

\section{DAFTAR PUSTAKA}

Chapman, Stephen N. 2006. The Fundamental of Production Planning and Control. New Jersey: Pearson Education, Inc.

David, Philip Kaminsky, Simchi-Levi, \& Edith Simchi-Levi. 2003. Designing and Managing the Supply Chain: Concepts, Strategies, and Case Studies (2 ${ }^{\text {nd }}$ ed). Singapore: McGraw-Hill.

Emmeett, Stuart. 2005. Excellence in Warehouse Management. West Sussex: John Willey \& Sons, Ltd.

Mulcahy, David E. 1994. Warehouse Distribution \& Operations Handbook. Singapore: McGrawHill Book Co.

Richards, Gwynne. 2011. Warehouse Management: A Complete Guide to Improving Efficiency and Minimizing Costs in the Modern Warehouse.

Tersine, Richard J. 1994. Principles of Inventory and Materials Management. USA: PTR PrenticeHall,Inc. 